\title{
D-optimal Design and Development of Microemulsion Based Transungual Drug Delivery Formulation of Ciclopirox Olamine for Treatment of Onychomycosis
}

\author{
P. CHOUHAN AND T. R. SAINI*
}

Industrial Pharmacy Research Lab, Department of Pharmacy, Shri G. S. Institute of Technology and Science, Indore, India

Chouhan and Saini: D-optimal Designing of Microemulsion of Ciclopirox Olamine

\begin{abstract}
The objective of the present study was to design and develop a microemulsion based transungual drug delivery formulation of ciclopirox olamine using colloidal carrier for treatment of onychomycosis. Capmul PG8 was selected as oil phase due to the high solubility of ciclopirox in it as compared to other oils and Cremophor EL and Transcutol $P$ were used as surfactant and cosurfactant respectively. Pseudoternary phase diagrams were constructed using different ratio of $S_{\text {mix }}$ (surfactant:cosurfactant). The phase diagram obtained from 1:3 ratio showed largest microemulsion region. The construction of microemulsion was further optimized by D-optimal mixture design, taking oil, $S_{\text {mix }}$ and water as independent variables and globule size, transungual flux, and nail drug loading as response variables. Mathematical equations and response surface plots were used to correlate the dependent and independent variables. The optimized composition of microemulsion was predicted by numerical optimization technique on the basis of the highest desirability value. The predicted optimized microemulsion which contained $2 \%$ oil, $40 \% \mathrm{~S}_{\text {mix }}$, and $58 \%$ water was incorporated into Carbopol 940 gel base and evaluated for transungual drug permeation. The optimized microemulsion based gel formulation showed globule size $(25.8 \pm 1.2 \mathrm{~nm})$, transungual flux $(0.436 \pm 0.014 \mu \mathrm{g} /$ $\left.\mathrm{cm}^{2} / \mathrm{h}\right)$, and drug loading in nail plate $(82.89 \pm 5.74 \mu \mathrm{g})$ which was in close agreement with the predicted value of response variable by the optimization software, i.e. $26.145 \mathrm{~mm}, 0.431 \mu \mathrm{g} / \mathrm{cm}^{2} / \mathrm{h}, \mathrm{and} 81.023 \mu \mathrm{g}$, respectively. These results confirmed that the D-optimal mixture design can be successfully employed for designing and development of microemulsion based formulation of ciclopirox olamine.
\end{abstract}

Key words: Microemulsion, ciclopirox olamine, pseudoternary phase diagram, transungual, optimization, D-optimal design

The human nail plate is the most resistant barrier of the nail structure for drug penetration and therefore it is very difficult to deliver drug through nail in transungual infections ${ }^{[1]}$. Onychomycosis, also known as tinea unguium, is the most common nail fungal disease affecting approximately $14 \%$ of the general population and $48 \%$ aged population ${ }^{[2-4]}$. It affects one or more components of nail apparatus, including the nail plate, the nail matrix, and the nail bed.

In the treatment of onychomycosis, the oral antifungal drug therapy remains the only choice due to deepseated persistent nature of the infectious fungi and limitation of topical route of drug administration due to poor drug permeation through nail plate ${ }^{[5,6]}$. A longduration oral antifungal therapy is, however, required to achieve therapeutic drug concentration in nail plate due to limited blood circulation at this site. This is often

*Address for correspondence E-mail: tsaini@sgsits.ac.in

July-August 2016 associated with serious side effects, drug interactions, and high recurrence rates. The problem of adverse effects of oral antifungal drug therapy can only be overcome if the drug delivery through nail plate could be realized ${ }^{[6]}$.

The human nail plate is a highly ordered and dense epidermal structure grossly made up of three distinct layers - a thin dorsal lamina, the thicker intermediate lamina, and a ventral layer from the nail bed (fig.1a). It composed of $\sim 80 \%$ sulfur-rich $\alpha$-keratin, $10-30 \%$

This is an open access article distributed under terms of the Creative Commons Attribution-NonCommercial-ShareAlike 3.0 License, which allows other the remix, tweak, and build up to the non-commercially, as long as the author is credited and the new creations are licensed under the identical terms.

Accepted 22 August 2016

Revised 18 August 2016

Received 29 May 2016

Indian J Pharm Sci 2016;78(4):498-511 
water, and $0.1-1 \%$ lipids. Due to the presence of plenty of disulfide and hydrogen bonds which interlink keratin fibers, the nail plate becomes an extremely impermeable structure of human body ${ }^{[7]}$. A variety of chemical permeation enhancers have been reported for enhancement of permeability of nail plate for topical administration of drugs. Keratolytic agents, e.g., urea and salicylic acid promote nail softening and swelling via denaturation of keratin fibers ${ }^{[8]}$. The sulfhydryl compounds, e.g., thioglycolic acid ${ }^{[9,10]}$, N-acetyl-1cysteine $^{[11,12]}, \mathrm{N}-\left(2-\right.$ mercaptopropionyl) glycine $^{[13]}$ and 2-mercaptoethanol ${ }^{[12]}$ significantly enhance porosity of nail plates.

Though, the colloidal carriers such as deformable lipid vesicles and microemulsions are well known for their potential transdermal applications, nevertheless, their applications in the field of transungual drug delivery have not been explored so far. In one research study, it was found that the transungual drug delivery via lateral diffusion to the nail bed from the surrounding skin tissues is possible. An o/w microemulsion containing an experimental drug (NB-002) effectively delivered across the skin present nearby nail plate ${ }^{[14]}$. In another attempt itraconazole could be delivered in nail plate through a $\mathrm{o} / \mathrm{w}$ microemulsion formulation applied on nail plate in an in vitro drug loading study ${ }^{[15]}$, other than this, microemulsion based gel of terbinafine showed better in vitro transdermal permeation compared to marketed formulation ${ }^{[16]}$.

The above findings undoubtedly prove that microemulsion is an effective carrier for transdermal drug delivery and it may be worthwhile to explore this attribute of microemulsion in the transungual applications. In this research paper, an attempt was made to use microemulsion carrier approach for transungual drug delivery of ciclopirox olamine. As the nail swells after water absorption and behaves like a hydrogel with a network of aqueous pores ${ }^{[8,17]}$, it was hypothesized that the nanosized microemulsion droplets would readily pass through them and this will pave the way for permeation of hydrophobic drug present in the oil droplets, across the nail plate (fig. 1b).

The microemulsion formulation is a complex mixture of oil, surfactant, cosurfactant, water, and drug and the majority of its properties are dependent upon the droplet size of internal phase. The primary objective of the present formulation development plan was to achieve a high and consistent transungual flux along with adequately large amount of drug loading in nail plate so that drug delivery at the deeply seated site of fungal infection in nail layers, could be ensured. Therefore, minimum droplet size of microemulsion, higher transungual flux, and maximum drug loading in nail plate were identified as the key requisites of the proposed formulation. These three key requisites were optimized by statistical experimental design technique employing D-optimal mixture design. In a mixture design experiment, factors are the components of a mixture and the response is function of proportions of each ingredient. In mixture design the proportion of each ingredient is more important than their respective

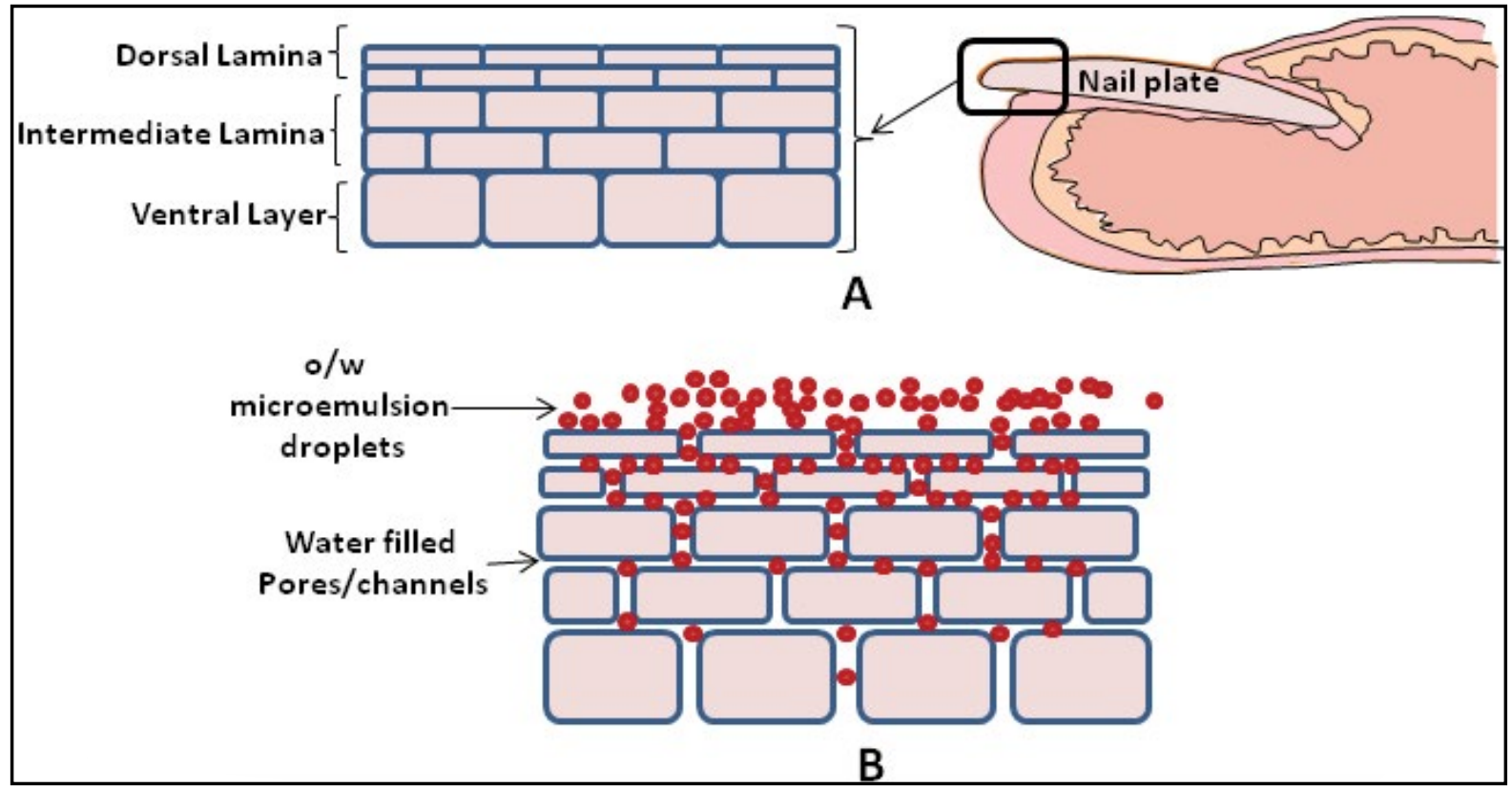

Fig. 1: Schematic diagram of nail and possible transport of formulation.

Schematic diagram of nail plate showing (A) different layers, and (B) possible transport of nanosized o/w microemulsion droplets in nail plate. 
amount in mixture as the components cannot range in an independent way since their sum has to be equal to $100 \% \mathrm{w} / \mathrm{w}^{[18]}$.

\section{MATERIALS AND METHODS}

Ciclopirox olamine (MW-268.36 Da) was obtained as a gift from Sifavitor Srl, Italy. Propylene glycol monocaprylate (Capmul ${ }^{\circledR}$ PG-8), medium chain mono and diglycerides (Capmul $\left.{ }^{\circledR} \mathrm{MCM}\right)$, were gift samples from ABITEC Corp., USA, highly purified diethylene glycol monoethyl ether (Transcutol ${ }^{\circledR} \mathrm{P}$ ), was gift sample from Gattefossé, France, polyoxyl 35 castor oil (Cremophor ${ }^{\circledR}$ EL), poloxamer 407, and poloxamer 188 were gifted by BASF, India. Benzyl alcohol, isopropyl myristate, isopropyl palmitate, castor oil, olive oil, oleic acid, polysorbate 80 (Tween ${ }^{\circledR} 80$ ), polyethylene glycol 400, glycerin, and ethanol were purchased from SD Fine-Chem, India. The HPLC grade acetonitrile was purchased from Merck, India and tyloxapol was purchased from Sigma Aldrich, India. All aqueous solutions were prepared in demineralized water (MilliQ water). All other chemicals used were of analytical grade.

\section{Nail clippings:}

The nail clippings were collected from healthy human volunteers (male and female, age 25-50 y) and washed three times with $70 \% \mathrm{v} / \mathrm{v}$ ethanol and then rinsed with deionized water and dried overnight in an open Petri dish at room temperature. The dried nail clippings were either used immediately or stored at controlled temperature $\left(2-8^{\circ}\right)$ in aluminum capped vials ${ }^{[7]}$. The thickness of each nail clipping was measured with a digital caliper (Micrometer MI-1000, Mititoyu, Japan) at three different points. Thickness of nail clippings used in the present studies was found to be in the range of 0.4-0.5 mm.

\section{Screening of formulation components:}

In the first step, the solubility of the drug in oils, surfactants, and cosurfactants was determined because the transungual permeability of drug is primarily dependant on its solubility in oils. Solubility of ciclopirox olamine in various oils, surfactants, and cosurfactants was determined by adding an excess amount of drug in $3 \mathrm{ml}$ of selected oils (Capmul PG-8, Capmul MCM, benzyl alcohol, castor oil, oleic acid, isopropyl palmitate, isopropyl myristate, olive oil, and sesame seed oil), $3 \mathrm{ml}$ of selected surfactants (Tween 80, tyloxapol, poloxamer 407, Cremophor EL, and poloxamer 188), and $3 \mathrm{ml}$ of selected cosurfactants (Transcutol P, polyethylene glycol 400, glycerin, and ethanol) separately in $5 \mathrm{ml}$ capacity stopper vials, and mixed using a vortex mixer. These vials were then kept at $25 \pm 1^{\circ}$ in a shaking water bath for $72 \mathrm{~h}$ to attain drug equilibrium solubility. The samples of each vial were removed from shaker and centrifuged at 3000 rpm for $15 \mathrm{~min}$. The supernatant was taken and filtered through a $0.45 \mu$ membrane filter. The concentration of ciclopirox olamine in the filtrate was determined using HPLC at $305 \mathrm{~nm}$ after appropriate dilution with methanol (Table 1).

Screening of surfactant was done on the basis of their oil accommodation capacity in fixed amount of water. For this, $10 \% \mathrm{w} / \mathrm{w}$ solutions of different surfactants were prepared in DM water. The selected oil was added to above surfactant solutions by an increment of $20 \mu \mathrm{l}$, after each addition the blends were mixed using a vortex mixer and clarity of each mixture was noted. Appearance of turbidity or phase separation was considered as the end point of experiment ${ }^{[19]}$.

As the cosurfactant works synergistically with surfactants, screening of the cosurfactant was also done. Blends of selected surfactant and various cosurfactants in the weight ratio of 75:25 (surfactant: cosurfactant) were prepared and in $10 \% \mathrm{w} / \mathrm{w}$ solution of these blends in DM water selected oil was added by an increment of $20 \mu 1$ and mixed well on a vortex mixer and clarity was noted. Appearance of turbidity or phase separation in the resulting mixtures was considered as the end point of experiment.

\section{Preparation of pseudoternary phase diagram:}

On the basis of the drug solubility and surfactantcosurfactant miscibility Capmul PG8, Cremophor EL, and Transcutol $\mathrm{P}$ were selected as the oil phase, surfactant, and cosurfactant respectively for phase

TABLE 1: SOLUBILITY OF CICLOPIROX OLAMINE IN VARIOUS COMPONENTS OF MICROEMULSION

\begin{tabular}{lc}
\hline \multicolumn{1}{c}{ Component } & Solubility* $(\mathrm{mg} / \mathrm{g})$ \\
\hline Capmul $^{\circledR}$ PG8 & $74.00 \pm 4.04$ \\
Capmul ${ }^{\circledR}$ MCM & $68.42 \pm 1.35$ \\
Benzyl alcohol & $51.42 \pm 1.21$ \\
Castor oil & $35.28 \pm 0.47$ \\
Oleic acid & $31.12 \pm 0.76$ \\
Isopropyl myristate & $10.45 \pm 0.35$ \\
Isopropyl palmitate & $6.80 \pm 1.33$ \\
Olive oil & $5.30 \pm 0.64$ \\
Sesame seed oil & $4.60 \pm 0.51$
\end{tabular}

${ }^{*}$ mean $\pm S D,(n=3)$ 
diagram study using DM water as an aqueous phase. Surfactant and cosurfactant were mixed in different weight ratios $(1: 1,1: 2,1: 3,2: 1$, and $3: 1)$ and named as $\mathrm{S}_{\text {mix }}$. The $\mathrm{S}_{\text {mix }}$ ratio was chosen in increasing concentration of surfactant with respect to cosurfactant and increasing concentration of cosurfactant with respect to surfactant. The pseudoternary phase diagrams were constructed by water titration method (fig. 1). The oil and $\mathrm{S}_{\text {mix }}$ were mixed thoroughly in different weight ratios ranging from 1:0 to $0: 1$ (1:0, $0.9: 0.1,0.8: 0.2, \quad 0.7: 0.3,0.6: 0.4,0.5: 0.5,0.4: 0.6$, $0.3: 0.7,0.2: 0.8,0.1: 0.9,0: 1)$ in different glass vials. The "water dilution lines" which represent increasing water content and decreasing $\mathrm{S}_{\text {mix }}$ levels were drawn. The water was titrated slowly with $\mathrm{S}_{\text {mix }}$ and visually observed for transparency or turbidity in the system. After every addition of water, the mixture was stirred on vortex mixer. If a clear and transparent mixture was obtained after stirring, the sample was considered monophasic. Every composition of monophasic emulsion was marked as a point in the phase diagram. The area covered by these points was considered to be the microemulsion region of existence.

\section{Optimization of microemulsion components:}

Five phase diagrams were obtained for five different $\mathrm{S}_{\text {mix }}$ ratios $(1: 1,1: 2,1: 3,2: 1$, and $3: 1)$. The $\mathrm{S}_{\text {mix }}$ ratio which produced broader microemulsion region was selected for formulation optimization.

\section{D-optimal design:}

The experimental mixture design technique is applied for optimization of variables when experimental responses are dependent only on the proportions of the ingredients of mixture. It is a type of response surface optimization technique in which design factors are the components of a mixture and responses are function of the proportions of each component. The mixture components cannot range in an independent way since their sum has to be equal to $100 \%{ }^{[18]}$. D-optimal mixture design is commonly used to reveal main effects and interaction effects between the independent variables of the experiment ${ }^{[20]}$.

Design-Expert 7.1 (Stat-Ease Inc., Minneapolis, USA) software program was used in the present studies for the experimental design. A single block D-optimal mixture design with 6 model points and 4 points to estimate the lack was employed to construct polynomial models. Different design constraints, i.e. A (oil), B $\left(\mathrm{S}_{\text {mix }}\right)$, and $\mathrm{C}$ (water) were taken at high and low levels (Table 1).
The sum of A, B, and C were kept fixed at $100 \%$. This design provided a 10 run empirical model to describe the effect of formulation ingredient on the globule size (D50), transungual drug permeation flux, and nail drug loading from microemulsion formulations. Validity of experimental design was confirmed by plotting a standard error of design graph. The probability value $(\alpha)$ for determination of statistical significance was set at 0.05 , which indicated that a "hypothesis" theory would be rejected if the calculated p-value was less than 0.05 in favor of an alternate theory. Models were selected on the basis of sequential comparison and lack of fit test. Significance of the models was further confirmed by statistical analysis. Response surface, contour plot, and overlay plots were constructed for the response variables.

\section{Preparation of microemulsion of ciclopirox olamine:}

The D-optimal design suggested 10 different combinations of oil, $\mathrm{S}_{\text {mix }}$, and water (Table 2). The suggested quantity of oil and $\mathrm{S}_{\text {mix }}$ was mixed using a vortex mixer to produce the oily phase, at this stage the ciclopirox olamine was dissolved in the oily phase. Finally water was added and mixed on vortex mixer at medium speed to obtain drug loaded microemulsion formulation.

\section{Determination of response variables:}

Globule size of the microemulsion was determined by photon correlation spectroscopy that analyzes the fluctuations in light scattering due to Brownian motion of the globules, using a nanoparticle size analyzer (Nanotrac Wave, Microtrac Inc., USA).

To determine transungual permeation of ciclopirox olamine from microemulsion formulations, an $e x$ vivo drug permeation study was conducted for a period of $120 \mathrm{~h}$ using vertical Franz diffusion cell apparatus (Permegear Inc., USA). The nail plates were hydrated for $24 \mathrm{~h}$ in phosphate buffer ( $\mathrm{pH} 7.4)$ and then mounted on nail adapters in such a way that the

TABLE 2: OIL ACCOMMODATION CAPACITY OF DIFFERENT SURFACTANTS

\begin{tabular}{lc}
\hline Surfactant & Oil accommodation capacity $(\mathrm{mg} / \mathrm{gm})$ \\
\hline Cremophor & $100 \pm 2.14$ \\
Tyloxapol & $40 \pm 0.75$ \\
Poloxamer 407 & $30 \pm 0.75$ \\
Tween ${ }^{\oplus 0}$ & $30 \pm 0.48$ \\
(Polysorbate 80) & \\
Poloxamer 188 & $20 \pm 0.27$ \\
\hline
\end{tabular}

${ }^{*}$ mean $\pm S D,(n=3)$ 
dorsal side of the nail faced the donor compartment of diffusion cell. Microemulsion formulation equivalent to $500 \mu \mathrm{g}$ drug was added to the donor compartment of diffusion cell. Effective diffusional area of the cell was $0.2 \mathrm{~cm}^{2}$. Receptor compartment was filled with $5 \mathrm{ml}$ phosphate buffer ( $\mathrm{pH} 7.4$ ) containing $0.5 \% \mathrm{w} / \mathrm{v}$ sodium lauryl sulphate and $0.01 \% \mathrm{w} / \mathrm{v}$ sodium azide as a microbial growth inhibitor. The drug permeation medium was stirred by externally driven, Teflon coated small magnetic bead. Temperature of the receptor compartment was maintained at $32 \pm 0.5^{\circ}$ by circulation of thermostatic water across the cells ${ }^{[7]}$, the aliquots of permeation fluid were collected at an interval of $24 \mathrm{~h}$ with replacement.

Amount of drug permeated in the permeation fluid was determined using a Dionex HPLC system (P680 HPLC Pump, and UVD170U detector, Dionex, USA). The chromatographic separation was performed on a base deactivated endcapped phenyl column (Thermo BDS Hypersil ${ }^{\circ}$ Phenyl; $\left.250 \times 4.6 \mathrm{~mm}, 5 \mu \mathrm{m}\right)$ at room temperature. The mobile phase consisted of ethylenediaminetetraacetic acid (EDTA) disodium salt in water (0.96 in 1000):acetonitrile:acetic acid $(60: 40: 0.1)^{[21]}$. It was filtered through $0.22 \mu \mathrm{m}$ nitrocellulose-membrane filter (Millipore, India) and degassed prior to use. The flow rate of $1 \mathrm{ml} / \mathrm{min}$ was maintained and the analyte was measured at $305 \mathrm{~nm}$. The injection volume was $20 \mu \mathrm{l}$ and total run time of each sample was 10 min.

Drug loading in nail plates was determined using modified nail digestion process reported by the authors $^{[7]}$. Nail clippings (used in drug permeation study) were wiped 3 times with damped cotton and dried with tissue paper. The washed nail clippings were dissolved in $1 \mathrm{M}$ sodium hydroxide $(1 \mathrm{ml})$ by constant stirring overnight. After complete digestion the nail clipping solution was acidified with $300 \mu \mathrm{l}$ of $5 \mathrm{M}$ hydrochloric acid and ciclopirox olamine was extracted by adding $6 \mathrm{ml}$ dichloromethane to each solution in a centrifuge tube and shaking manually for $30 \mathrm{~min}$. The mixture was centrifuged at $4000 \mathrm{rpm}$ for 5 min. Drug rich lower organic phase was collected and evaporated at room temperature under vacuum using a rotary evaporator (R205, BÜCHI Labortechnik AG). The dried residue was washed three times with $2 \mathrm{ml}$ methanol and collected in screw capped test tubes. Collected solutions were filtered through $0.22 \mu \mathrm{m}$ syringe filter and analyzed by HPLC method. This extraction procedure was duly validated by spiking different drug concentrations $(2-10 \mu \mathrm{g} / \mathrm{ml})$ into 10 $\mathrm{mg} / \mathrm{ml}$ nail plate solution prepared in $1 \mathrm{M}$ sodium hydroxide. The recovery was found to be $90.22 \pm 7.68 \%$.

The microemulsion composition was optimized by numerical optimization technique. The desirable objectives of optimization were (a) the globule size of microemulsion should be minimum, (b) the transungual flux should be maximum, and (c) the drug loading in nail should be maximum. To achieve these desired criteria, two solutions were predicted by the software and the solution that had higher desirability value $(0.996)$ was selected as the optimized formulation composition. The predicted optimized microemulsion formulation contained $2 \%$ oil, $40 \% \mathrm{~S}_{\text {mix }}$, and $58 \%$ water.

The predicted optimized microemulsion of ciclopirox olamine was prepared by mixing oil $(2 \% \mathrm{w} / \mathrm{w})$ and $\mathrm{S}_{\text {mix }}$ $(40 \% \mathrm{w} / \mathrm{w})$ together in a vortex mixer, and ciclopirox olamine was dissolved in it. Finally water $(58 \% \mathrm{w} / \mathrm{w})$ was added and mixed on vortex mixer to obtain drug loaded microemulsion formulation.

\section{Characterization of optimized microemulsion of ciclopirox olamine:}

The rheological property of the optimized microemulsion formulation was evaluated by a rheometer (R/S-CPS-P1, Brookfield, Stoughton, $\mathrm{MA})$ at $30^{\circ}$ using a $\mathrm{C} 50-1$ cone/plate system at 500 rpm. Electrical conductivity was measured using a conductivity meter (JSI-1006, Jyoti, India) and based on electrical conductivity, the phase system of the microemulsion was determined. The clarity of optimized microemulsion was evaluated by measuring the transmittance $(\% \mathrm{~T})$ at $650 \mathrm{~nm}$ using $\mathrm{UV} /$ visible spectrophotometer (UV 1700, Shimadzu, Japan) keeping distilled water as a blank. The refractive index of optimized microemulsion was measured with Abbe refractometer (Scientech, India). The optimized microemulsion was centrifuged at $12000 \mathrm{rpm}$ for 30 min using a cooling centrifuge (Centrifuge 5415R, Eppendorf $\mathrm{AG}$ ) for determination of their physical stability.

The morphology of optimized microemulsion was observed using transmission electron microscopy, TEM (Tecnai 20, Philips, Holland). One drop of microemulsion was deposited on a film-coated copper grid and later stained with one drop of $2 \% \mathrm{w} / \mathrm{v}$ aqueous solution of phosphotungstic acid and allowed to dry before examination under microscope. For determination of colloidal nature, the microemulsion was observed under cross polarized light using a 
polarizing microscope (DM1000, Leica Microsystems, Germany). The globule size, transungual flux, and drug loading in nail of the optimized microemulsion were also determined using similar procedure as mentioned earlier.

\section{Drug release from optimized microemulsion of ciclopirox olamine:}

The drug release study was performed using a regenerated seamless cellulose dialysis membrane of molecular weight cutoff of 12-14 KDa (LA395-1MT, HiMedia Laboratories Pvt. Ltd., India). The membrane was activated prior to use by incubating in $5 \% \mathrm{w} / \mathrm{v}$ EDTA solution for $30 \mathrm{~min}$ and then in boiling water for $1 \mathrm{~h}$. The microemulsion formulation equivalent to 10 mg drug was placed into the treated dialysis tube and a sac was prepared by tightening their open ends with a cotton thread. Dialysis sacs containing the formulation were dipped into $100 \mathrm{ml}$ phosphate buffer ( $\mathrm{pH}$ 7.4) containing $0.5 \% \mathrm{w} / \mathrm{v}$ sodium lauryl sulfate (SLS) as drug release medium which was uniformly mixed and the temperature was controlled using a water bath at $32 \pm 0.5^{\circ}$. The drug release study was performed for $6 \mathrm{~h}$ and at every sampling point $5 \mathrm{ml}$ aliquot of drug release fluid was withdrawn and replaced with equal amount of fresh drug release medium. The withdrawn fluid samples were analyzed for drug content using HPLC method.

\section{Preparation of microemulsion based gel formulation of ciclopirox olamine:}

Appropriate quantity of Carbopol $940(1 \%$ w/w) was added to demineralized water and mixed using a mechanical stirrer (RQ-122, Remi Elektrotecknik Ltd, India). This mixture was agitated at slow speed for $30 \mathrm{~min}$ then the mixture was allowed to hydrate and swell for $60 \mathrm{~min}$. The resultant hydrated mixture was then neutralized with triethylamine (98\%) until approximately $\mathrm{pH} 7$ was achieved, during the neutralization process; the mixture was stirred gently with a glass rod until homogeneous gel was formed.

The optimized microemulsion of ciclopirox olamine was incorporated in above gel base in sufficient amount so as to obtain $1 \% \mathrm{w} / \mathrm{w}$ concentration of ciclopirox olamine to the weight of final gel formulation.

\section{Drug release from formulated microemulsion-based gel of ciclopirox olamine:}

The optimized microemulsion and microemulsionbased microemulsion-based gel formulation was evaluated for drug release so as to determine the possible matrix effect on release of ciclopirox olamine due to incorporation of microemulsion in Carbopol 940 gel. Drug release study from a solution of ciclopirox olamine $(5 \mathrm{mg} / \mathrm{ml})$ in phosphate buffer ( $\mathrm{pH} 7.4$ ) containing $0.5 \% \mathrm{w} / \mathrm{v}$ SLS was also performed as a control run. The dialysis membrane was activated prior to use by incubating in $5 \% \mathrm{w} / \mathrm{v}$ EDTA solution for $30 \mathrm{~min}$ and then in boiling water for $1 \mathrm{~h}$. The drug solution and microemulsion-based gel formulation equivalent to $10 \mathrm{mg}$ ciclopirox olamine was placed into the treated dialysis membrane and a sac was prepared by tightening their open ends with a cotton thread. The sacs containing drug solution and microemulsion formulation were dipped into $100 \mathrm{ml}$ phosphate buffer ( $\mathrm{pH} 7.4$ ) containing $0.5 \% \mathrm{w} / \mathrm{v}$ SLS as drug release medium which was uniformly mixed and the temperature was controlled using a water bath at $32 \pm 0.5^{\circ}$. The drug release study was performed for $6 \mathrm{~h}$ and at every sampling point $5 \mathrm{ml}$ aliquot of drug release fluid was withdrawn and replaced with equal amount of fresh drug release medium. The withdrawn fluid samples were analyzed for drug content using HPLC method.

\section{RESULTS AND DISCUSSION}

Selection of appropriate formulation components is an important exercise in the preparation of a stable microemulsion formulation. Higher solubility of the drug in oil phase was the main criterion for selection of oil; as it is important to maintain the drug in solubilized form in microemulsion formulation. The solubility of ciclopirox olamine was found to be highest in Capmul PG8 $(74.0 \pm 4.04 \mathrm{mg} / \mathrm{g})$, followed by Capmul MCM $(68.42 \pm 1.35 \mathrm{mg} / \mathrm{g})$, benzyl alcohol $(51.42 \pm 1.21 \mathrm{mg} / \mathrm{g})$, castor oil $(35.28 \pm 0.47 \mathrm{mg} / \mathrm{g})$, oleic acid $(31.12 \pm 0.76$ $\mathrm{mg} / \mathrm{g}$ ), isopropyl myristate, isopropyl palmitate, olive oil, and sesame seed oil (Table 1). Hence, Capmul PG8 was selected as the oil phase.

The toxicity of nonionic surfactants is generally lesser than ionic surfactants, besides they have lower critical micelle concentration (CMC) and offer better in vivo stability of $\mathrm{o} / \mathrm{w}$ microemulsion dosage forms ${ }^{[19]}$. Therefore the screening of surfactant was done from amongst the nonionic surfactants only. The surfactants were screened based upon their capacity to dissolve higher amount of oil (Capmul PG8) in their 10\%w/w aqueous solution ${ }^{[19]}$. Amongst all the surfactants, Cremophor EL accommodated highest amount of oil $(100 \pm 2.14 \mathrm{mg} / \mathrm{g})$ followed by tyloxapol $(40 \pm 0.75$ $\mathrm{mg} / \mathrm{g})$, poloxamer $407(30 \pm 0.75 \mathrm{mg} / \mathrm{g})$, Tween 80 
$(30 \pm 0.48 \mathrm{mg} / \mathrm{g})$, and poloxamer $188(20 \pm 0.27 \mathrm{mg} / \mathrm{g})$ (Table 2). Therefore, Cremophor EL was selected as the surfactant for microemulsion formulation development. Similarly, Transcutol P was selected as the cosurfactant as it accommodated highest amount of oil $(140 \pm 4.25 \mathrm{mg} / \mathrm{g})$ as compared polyethylene glycol $400(120 \pm 2.45 \mathrm{mg} / \mathrm{g})$ and propylene glycol $(110 \pm 3.24$ $\mathrm{mg} / \mathrm{g}$, Table 3). Thus, Capmul PG8, Cremophor EL, and Transcutol P were finally selected as the optimized oil, surfactant, and cosurfactant phases for the formulation of microemulsion of ciclopiroxolamine.

fig. 2 presents the pseudoternary phase diagrams with various weight ratios of Cremophor EL/Transcutol P. The transparent region of zone of microemulsion existence is presented in phase diagrams. The rest of the region on the phase diagram represents the biphasic, turbid, and conventional emulsions based on visual observation. The total area under the microemulsion zone in fig. 2 was inversely proportional to the ratio of $\mathrm{S}_{\text {mix }}$. The area of microemulsion zone became enlarged as $\mathrm{S}_{\text {mix }}$ ratio decreased, reaching the maximum point at $\mathrm{S}_{\text {mix }}$ of 1:3. Therefore, the pseudoternary phase diagram prepared from $\mathrm{S}_{\text {mix }}$ ratio 1:3 was further utilized for selecting the optimization boundaries for different components of microemulsion.

The D-optimal mixture design is preferred for optimization of formulations containing mixtures and when limitations and restrictions regarding the experimental designs are more as it needs lesser optimization trials as compared to other optimization techniques.

The component restrictions for experimental design (Table 4) were based on the microemulsion zone of pseudoternary phase diagram $\left(\mathrm{S}_{\text {mix }} 1: 3\right)$. Chemically nail plates are composed of $80 \%$ fibrous keratin protein and $0.1-1 \%$ lipid $^{[22]}$. Therefore, the nail swells as water is absorbed and the hydrated nail behaves like a hydrogel

\section{TABLE 3: OIL ACCOMMODATION CAPACITY OF DIFFERENT SURFACTANT-COSURFACTANT BLENDS}

\begin{tabular}{|c|c|}
\hline $\begin{array}{l}\text { Surfactant-cosurfactant } \\
\text { blend }\end{array}$ & $\begin{array}{c}\text { Oil accommodation } \\
\text { capacity (mg/gm) }\end{array}$ \\
\hline Cremophor ${ }^{\circledR}$ EL-Transcutol ${ }^{\circledR} \mathrm{P}$ & $140 \pm 4.25$ \\
\hline $\begin{array}{l}\text { Cremophor }{ }^{\circledR} \text { EL-polyethylene } \\
\text { glycol } 400\end{array}$ & $120 \pm 2.45$ \\
\hline $\begin{array}{l}\text { Cremophor }{ }^{\circledast} \text { EL-propylene } \\
\text { glycol }\end{array}$ & $110 \pm 3.24$ \\
\hline Cremophor $^{\circledast}$ EL-glycerin & $100 \pm 1.48$ \\
\hline Cremophor ${ }^{\circledR}$ EL-ethanol & $100 \pm 1.24$ \\
\hline
\end{tabular}

${ }^{*}$ mean $\pm S D,(n=3)$

July-August 2016 with a dense network of watery pores through which molecules can permeate ${ }^{[8,23]}$. Most of the antifungal drugs available in the market are lipophilic in nature, but unfortunately the nail structure contains very little lipid to support their permeation. Therefore, it was planned to keep the amount of oil as low as possible $(2-10 \%)$. Water is an effective plasticizer for the nai ${ }^{[17]}$. The nail contains $10-30 \%$ water, which not only imparts flexibility to it but controls its barrier property for drug molecules also ${ }^{[23]}$. Once hydrated, the nail becomes more elastic and very likely more permeable to a topically applied substance ${ }^{[17]}$. Therefore, the proportion of water was kept as the highest (40-58\%). Cremophor EL and Transcutol $\mathrm{P}$ are also reported to be good permeation enhancers for transdermal applications ${ }^{[24,25]}$, therefore their amount was also kept at higher side to drive additional advantage of their permeation enhancement effect $(40-50 \%)$ apart from their basic function of surfactant/cosurfactant.

For the optimization of ciclopirox olamine microemulsion formulation, 10 experiments were designed and then experimentally performed (Table 5). Three independent variables, oil $\left(X_{1}\right), S_{\text {mix }}\left(X_{2}\right)$, and water $\left(\mathrm{X}_{3}\right)$ and 3 response variables, globule size $\left(\mathrm{Y}_{1}\right)$, transungual flux $\left(\mathrm{Y}_{2}\right)$, and drug loading in nail $\left(\mathrm{Y}_{3}\right)$ were selected for the optimization study.

Selection of the optimization model that best describes and fits the obtained data is the first step towards an optimal statistical analysis. Therefore, different models, viz., linear, quadratic, cubic, and special cubic, were first analyzed for the response variables ( $\mathrm{Y}_{1}$ to $\mathrm{Y}_{3}$ ) by the predicted residual sum of square (PRESS) statistic for determination of suitability of model fitting. The PRESS statistic basically analyzes the prediction ability of the fitted models and the model with minimum value of PRESS statistic is usually considered as the most predictive model for the given set of data ${ }^{[16]}$. The quadratic model was selected for all three response variables as they observed the smallest value of PRESS statistic as compared to other three models (Table 6). Table 7 enlists other statistical data of the selected models of all three response variables. The adjusted R-squared and predicted R-squared values did not have a difference greater than 0.2 ; this further confirmed the suitability of the selected models. An ANOVA test was also performed by the software to predict the significance of model fitting. Table 8 showed the results of ANOVA for all the three variables. The values of Prob $>F$ was less than 0.05 , which indicated that model terms were significant. 

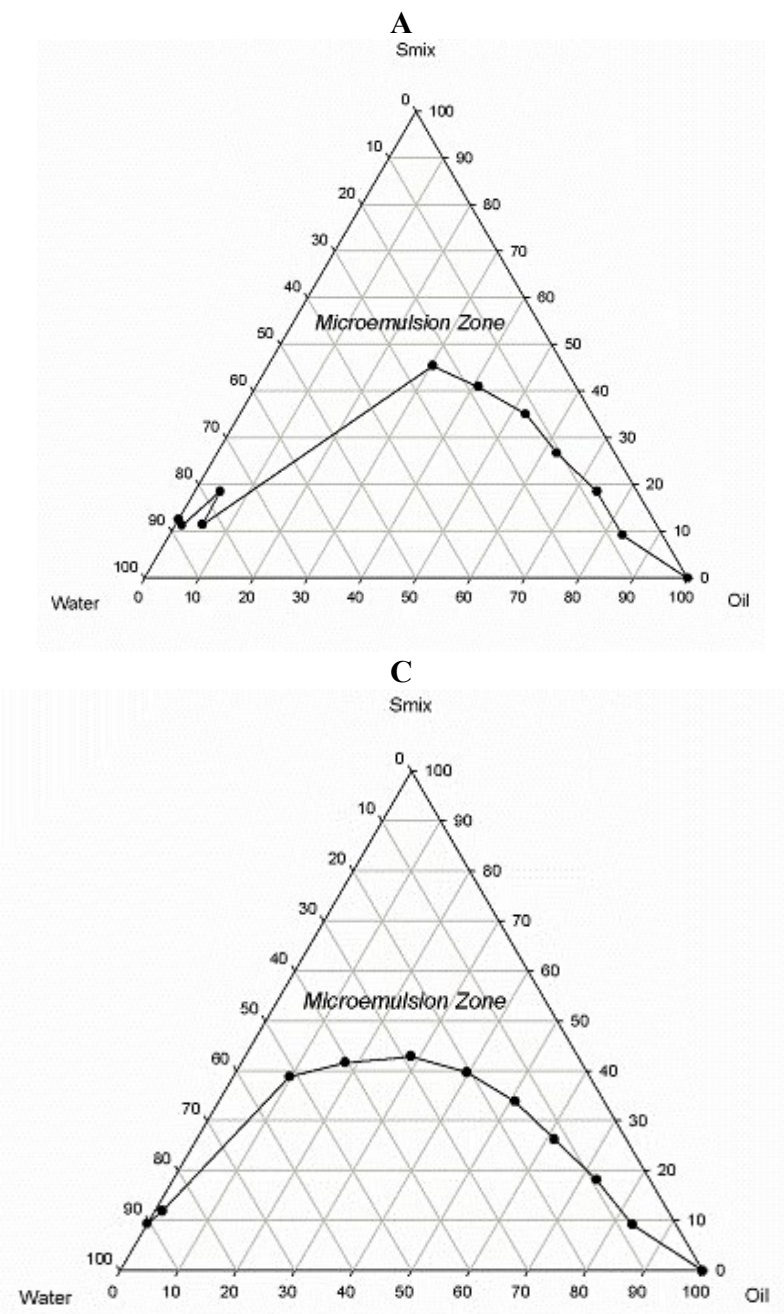
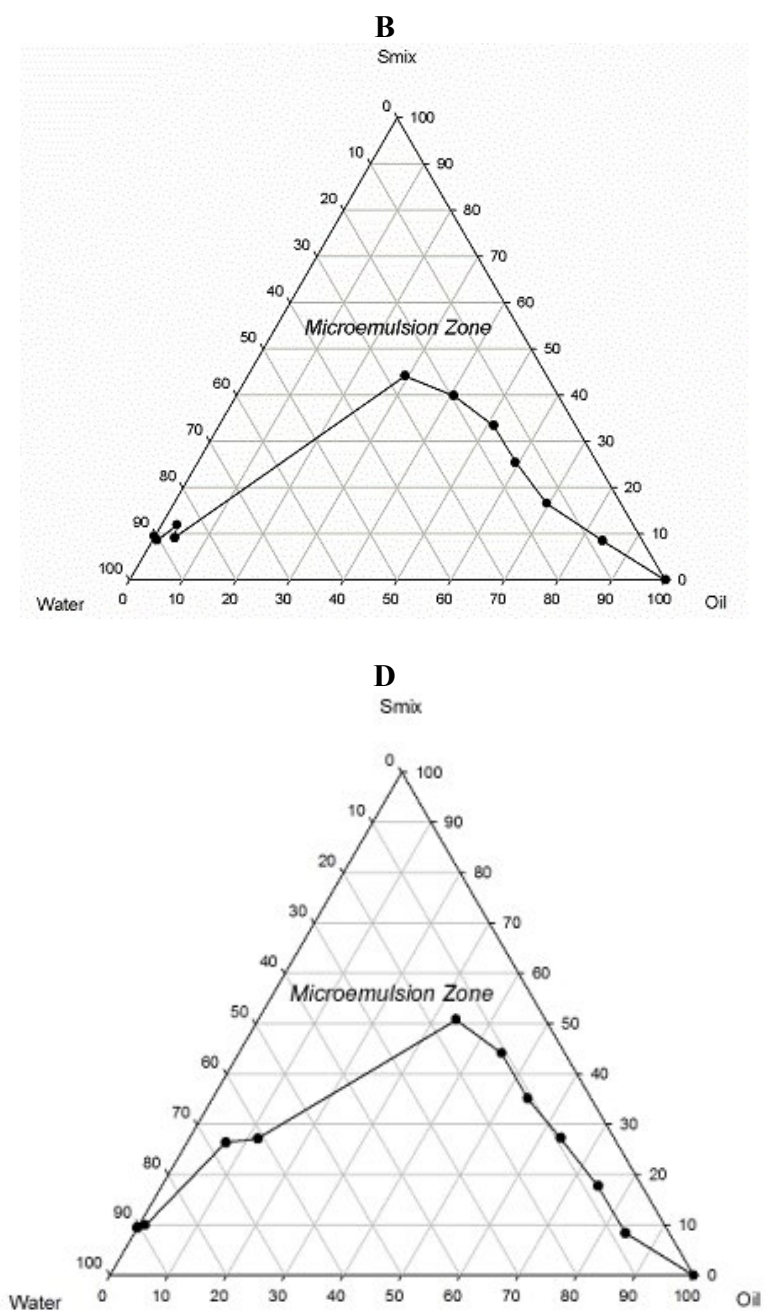

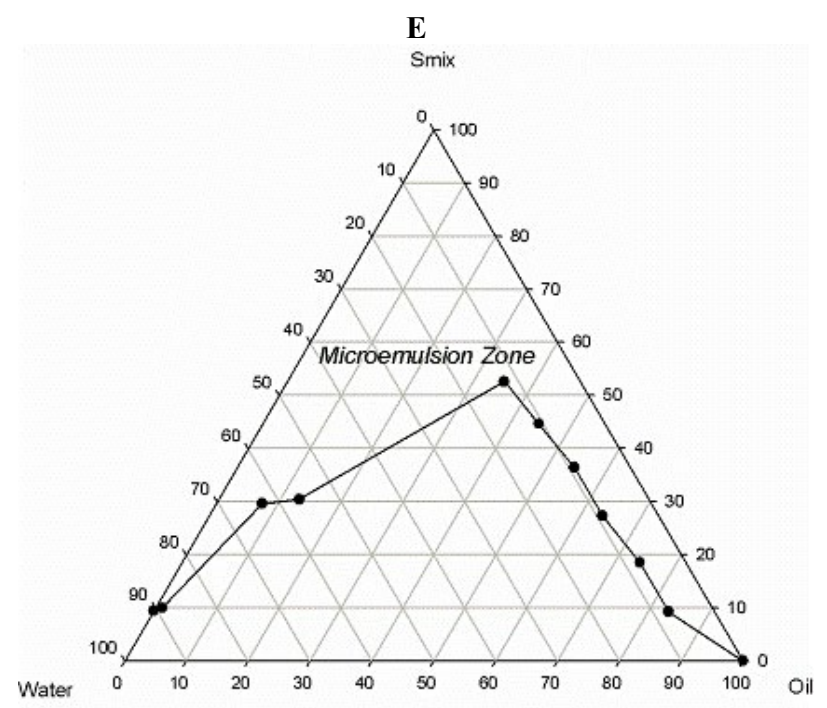

Fig. 2: Pseudoternary phase diagrams of microemulsions.

Pseudoternary phase diagrams of microemulsions composed of oil phase (Capmul PG8), surfactant (Cremophor EL), cosurfactant (Transcutol P), and water; A. $S_{\text {mix }} 1: 1, B . S_{\text {mix }} 1: 2, C . S_{\text {mix }} 1: 3, D . S_{\text {mix }} 2: 1, S_{\text {mix }} 3: 1$.

The adequate precision which measures the signal to noise ratio was also calculated, the obtained value was greater than the desirable value of 4 .
Following polynomial equations were derived and used to demonstrate the relationship between the formulation components: oil $\left(\mathrm{X}_{1}\right), \mathrm{S}_{\text {mix }}\left(\mathrm{X}_{2}\right)$, water $\left(\mathrm{X}_{3}\right)$, and the response variables $\mathrm{Y}_{1}$ to $\mathrm{Y}_{3}$. 
TABLE 4: RESTRICTIONS OF COMPONENT PROPORTIONS IN THE EXPERIMENTAL DESIGN

\begin{tabular}{lcc}
\hline Design constraint & Low level & High level \\
\hline X1 (\% of Oil) & 2 & 10 \\
X2 (\% of ${ }_{\text {Smix }}$ ) & 40 & 50 \\
X3 (\% of Water) & 40 & 58 \\
\hline
\end{tabular}

TABLE 5: D-OPTIMALEXPERIMENTAL PLAN FOR THE OPTIMIZATION OF MICROEMULSION COMPOSITION OF CICLOPIROX OLAMINE

\begin{tabular}{|c|c|c|c|c|c|c|}
\hline \multirow{2}{*}{ Run } & \multicolumn{3}{|c|}{ Independent variable } & \multicolumn{3}{|c|}{ Response variable } \\
\hline & $X_{1}(\% w / w)$ & $X_{2}(\% \mathrm{w} / \mathrm{w})$ & $\mathrm{X}_{3}(\% \mathrm{w} / \mathrm{w})$ & $\mathrm{Y}_{1}{ }^{\mathrm{a}}(\mathrm{nm})$ & $\mathrm{Y}_{2}^{\mathrm{a}}\left(\mu \mathrm{g} / \mathrm{cm}^{2} / \mathrm{h}\right)$ & $Y_{3}{ }^{a}(\mu g)$ \\
\hline 1 & 6 & 45 & 49 & 53.4 & 0.256 & 46.73 \\
\hline 2 & 6 & 40 & 54 & 69.3 & 0.266 & 48.56 \\
\hline 3 & 2 & 50 & 48 & 43.6 & 0.296 & 64.03 \\
\hline 4 & 10 & 45 & 45 & 135.9 & 0.198 & 41.67 \\
\hline 5 & 10 & 40 & 50 & 194.6 & 0.164 & 33.2 \\
\hline 6 & 2 & 45 & 53 & 34.4 & 0.396 & 73 \\
\hline 7 & 2 & 40 & 58 & 29.87 & 0.428 & 81.57 \\
\hline 8 & 6 & 50 & 44 & 76.6 & 0.191 & 36.12 \\
\hline 9 & 6 & 42.5 & 51.5 & 59.7 & 0.265 & 48.88 \\
\hline 10 & 10 & 50 & 40 & 109.9 & 0.170 & 34.76 \\
\hline
\end{tabular}

${ }^{a}$ Mean $\pm S D(n=3)$

TABLE 6: PRESS STATISTICS COMPARISON FOR RESPONSE VARIABLES

\begin{tabular}{lccc}
\hline & \multicolumn{3}{c}{ PRESS statistic value } \\
\cline { 2 - 4 } Type of model & \multicolumn{3}{c}{ Response variables } \\
& Y1 & Y2 & 885.92 \\
Linear & 13323.62 & 0.024 & 294.02 \\
Quadratic & 8231.21 & $6.052 E^{-004}$ & 464.47 \\
Special cubic & 15239.65 & $1.267 \mathrm{E}^{-003}$ & + \\
Cubic & + & + & + \\
\hline
\end{tabular}

+ Case(s) with leverage of 1.0000: PRESS statistic not defined

TABLE 7: SUMMARY STATISTICS FOR THE RESPONSE VARIABLES

\begin{tabular}{cccccccc}
\hline $\begin{array}{c}\text { Response } \\
\text { variable }\end{array}$ & $\begin{array}{c}\text { Predicted } \\
\text { model }\end{array}$ & F value & df* & $\begin{array}{c}\text { P-value } \\
\text { (Prob }>\text { F) }\end{array}$ & R-squared & $\begin{array}{c}\text { Adjusted } \\
\text { R-squared }\end{array}$ & $\begin{array}{c}\text { Predicted } \\
\text { R-squared }\end{array}$ \\
\hline Y1 & Quadratic & 9.53 & 3 & 0.0271 & 0.9889 & 0.9751 & 0.9321 \\
Y2 & Quadratic & 202.084 & 3 & 0.0001 & 0.9991 & 0.9980 & 0.9918 \\
Y3 & Quadratic & 19.417 & 3 & 0.0076 & 0.9896 & 0.9766 & 0.8827 \\
\hline
\end{tabular}

*df is degree of freedom

TABLE 8: ANOVA TESTING OF THE MODEL FITTING AND CALCULATED ADEQUATE PRECISION

\begin{tabular}{cccccccc}
\hline $\begin{array}{c}\text { Response } \\
\text { variable }\end{array}$ & Source & $\begin{array}{c}\text { Sum of } \\
\text { squares }\end{array}$ & df* & Mean squares & F value & $\begin{array}{c}\text { P-value } \\
\text { (Prob }>\text { F) }\end{array}$ & $\begin{array}{c}\text { Adequate } \\
\text { precision }\end{array}$ \\
\hline Y1 & Quadratic model & 23556.79 & 5 & 4711.36 & 25.03 & 0.0041 & 15.061 \\
Y2 & Quadratic model & 0.074 & 5 & 0.015 & 917.20 & 0.0001 & 85.254 \\
Y3 & Quadratic model & 2479.73 & 5 & 495.95 & 76.07 & 0.0005 & 23.214 \\
\hline
\end{tabular}

*df is degree of freedom

$\mathrm{Y}_{1}=+275.76 \times \mathrm{X}_{1}+320.88 \times \mathrm{X}_{2}+116.53 \times \mathrm{X}_{3}-1112.45 \times \mathrm{X}_{1} \mathrm{X}_{2}-$ $536.21 \times \mathrm{X}_{1} \mathrm{X}_{3}-177.60 \times \mathrm{X}_{2} \mathrm{X}_{3}-$ Eqn. 1

$\mathrm{Y}_{2}=+0.89 \times \mathrm{X}_{1}-0.013 \times \mathrm{X}_{2}+0.17 \times \mathrm{X}_{3}+0.18 \times \mathrm{X}_{1} \mathrm{X}_{2}-$ $0.78 \times \mathrm{X}_{1} \mathrm{X}_{3}+0.40 \times \mathrm{X}_{2} \mathrm{X}_{3}$-Eqn. 2

$\mathrm{Y}_{3}=+215.42 \times \mathrm{X}_{1}+10.78 \times \mathrm{X}_{2}+35.11 \times \mathrm{X}_{3}-83.87 \times \mathrm{X}_{1} \mathrm{X}_{2}{ }^{-}$ $216.13 \times \mathrm{X}_{1} \mathrm{X}_{3}+54.90 \times \mathrm{X}_{2} \mathrm{X}_{3}$-Eqn. 3 
was no need for data transformation for further analysis as the data were statistically significant for the prediction. Overlay plot (fig. 3) was produced by graphical optimization technique which highlighted the area of optimization in the pseudoternary diagram with minimum and maximum limits of the response variables as a function of independent variables.

Optimization of each formulation component was performed by fitting desired response objectives in the designed model. The effect of formulation components on the response $Y_{1}$ to $Y_{3}$ is graphically presented in fig. 4 as a two dimensional and 3D contour plot. The contour plot of globule size ( $\mathrm{Y}_{1}$, fig. 4a) showed that the globule size increases with the increase in oil proportion, but this effect was reversed in case of $\mathrm{S}_{\text {mix }}$ and water. Increase in composition of $\mathrm{S}_{\text {mix }}$ and water led to decrease in globule size. The effect of formulation components on transungual flux $\left(\mathrm{Y}_{2}\right)$ is shown in fig. $4 \mathrm{~b}$. It was observed that increase in concentration of oil in microemulsion reduces the transungual flux. This could be due to increase in the globule size as a result of increased oil proportion which led to reduced penetration of bigger oil droplets into deep layers of nail plate. Other two ingredients namely water, $\mathrm{S}_{\text {mix }}$ have positive effect on the flux. The increased proportion of $\mathrm{S}_{\text {mix }}$ resulted in reduction of globule size and thereby the permeation was increased, apart from this surfactant (Cremophor EL) and cosurfactant (Transcutol P) both would facilitate the drug permeation across the nail plate. Water increases hydration of nail plate and thereby increases its porosity, also it led to formation of smaller droplet which could further increase the drug permeation. The contour plot of drug loading in nail plate $\left(\mathrm{Y}_{3}\right.$, fig. 4c) showed that the drug loading increases with decrease in oil proportion and increase in proportion of $\mathrm{S}_{\text {mix }}$ and water.

The optimization of microemulsion formulation was performed using numerical optimization technique, where the optimization is based upon the desirability. Defining the constraints is an important step for achieving desirability. Table 9 enlists different constraints decided for numerical optimization. Based on the desired criteria, two optimized solutions were predicted by the software and the solution that had higher desirability value (0.996) was selected as the optimized formulation. The predicted optimized microemulsion formulation contained $2 \%$ oil, $40 \% \mathrm{~S}_{\text {mix }}$, and $58 \%$ water. The predicted optimized microemulsion formulation was prepared in triplicate and evaluated for response variables. The globule size, transungual flux, and drug loading in nail plate were obtained as $25.8 \pm 1.2 \mathrm{~nm}, 0.436 \pm 0.014 \mu \mathrm{g} / \mathrm{cm}^{2} / \mathrm{h}$, and $82.89 \pm 5.74 \mu \mathrm{g}$, respectively which were in close agreement with the predicted value suggested by the software (Table 10). Percentage prediction error was also calculated which was obtained as less than $3 \%$, which also confirmed the validity of D-optimal mixture design for optimization of microemulsion formulation.

The TEM image (fig. 5) shows the morphological characteristics of optimized microemulsion formulation. The droplets appeared dark, spherical in shape in bright background. The transparency of microemulsion was

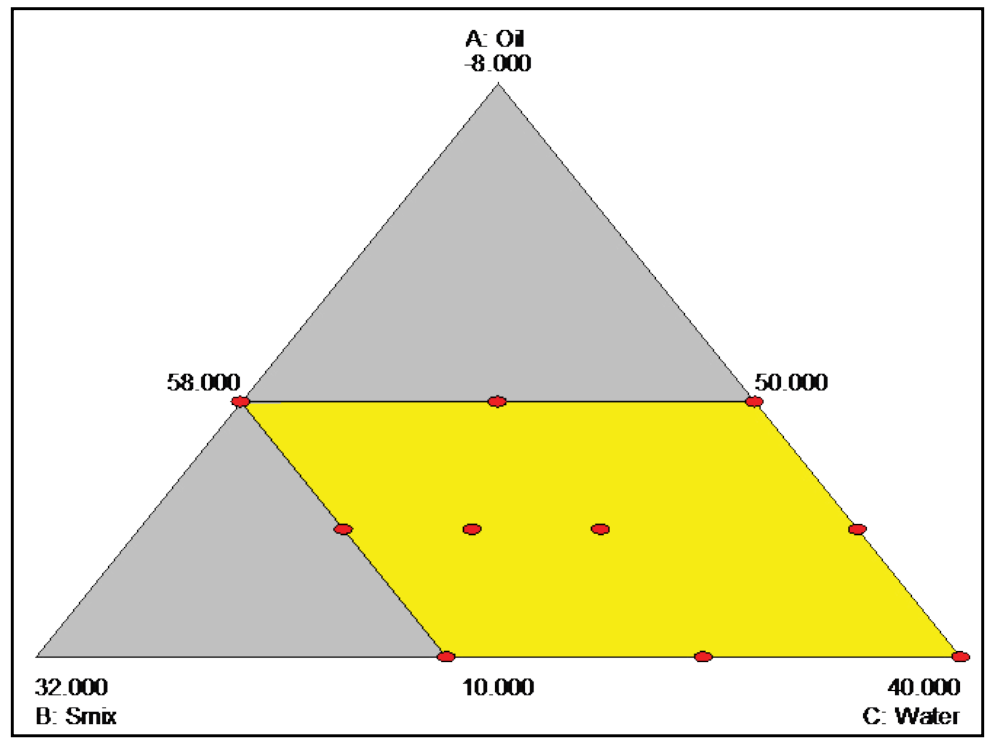

Fig. 3: Overlay plot. Overlay plot produced by graphical optimization technique highlighting area in which optimization was performed. $\bullet$ Design points. 

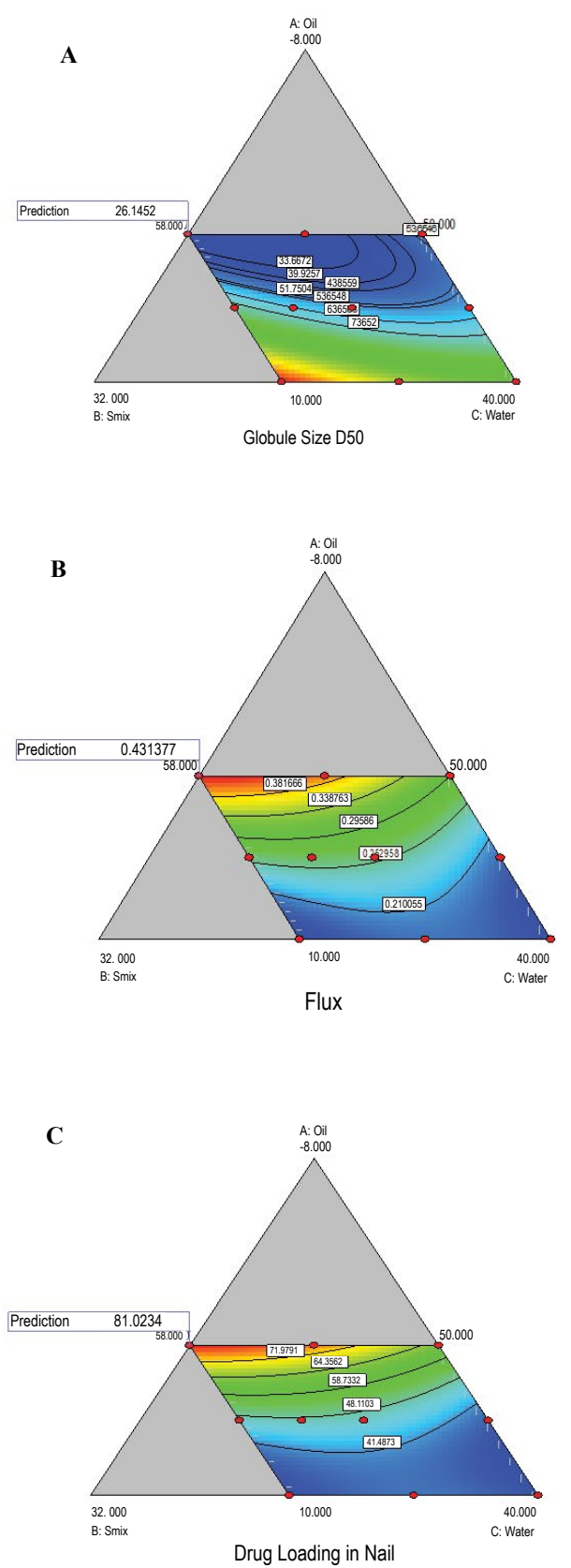
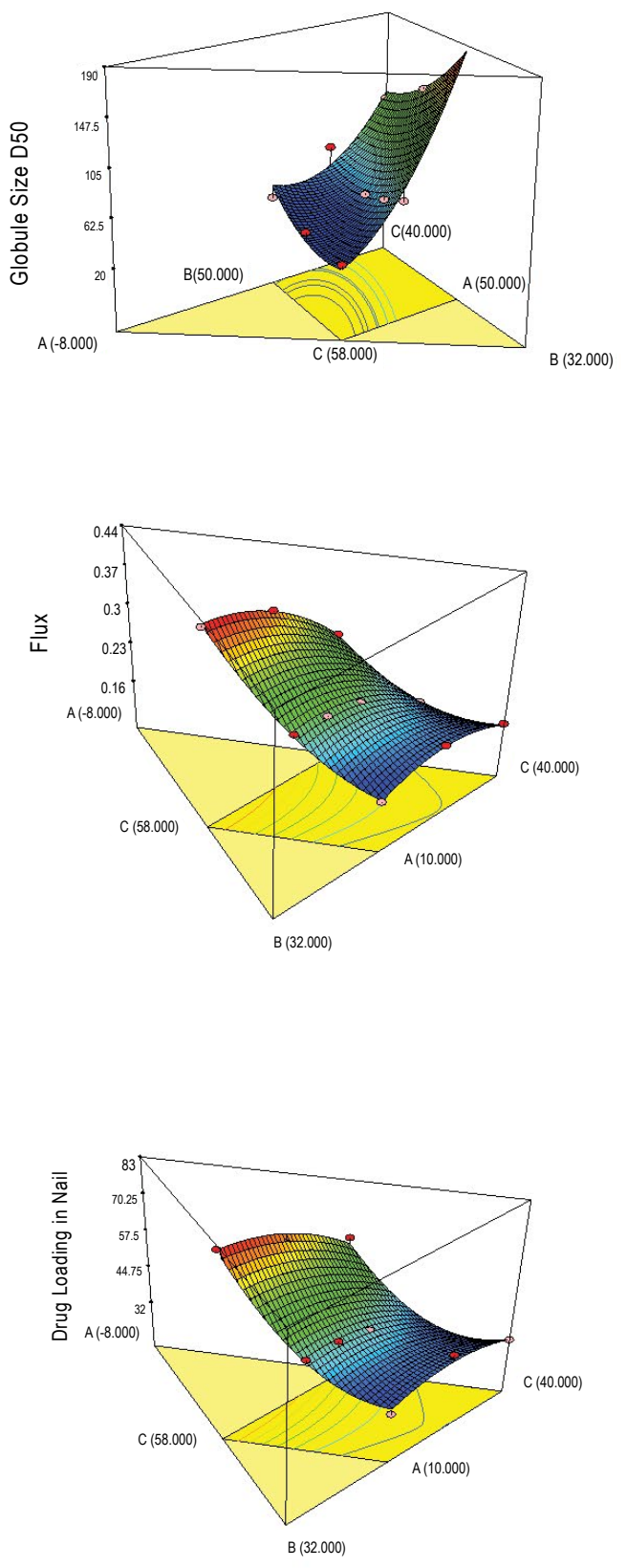

Fig. 4: Contour plots and 3D response-surface plots.

Contour plots and 3D response-surface plots showing the effect of formulation variables and prediction of optimum response of (A) globule size, (B) flux, (C) drug loading in nail plates.

\section{TABLE 9: CONSTRAINTS FOR NUMERICAL OPTIMIZATION}

\begin{tabular}{lccc}
\hline Variable & \multicolumn{3}{c}{ Constraints } \\
\cline { 2 - 4 } & Goal & Lower limit & Upper limit \\
\hline Oil $(\%)$ & In range & 2 & 10 \\
$\mathrm{~S}_{\text {mix }}(\%)$ & In range & 40 & 50 \\
Water $(\%)$ & In range & 40 & 58 \\
Globule size $(\mathrm{nm})$ & Minimize & 29.87 & 194.6 \\
Flux $\left(\mu \mathrm{g} / \mathrm{cm}^{2} / \mathrm{h}\right)$ & Maximize & 0.164 & 0.428 \\
Drug loading in nail $(\mu \mathrm{g})$ & Maximize & 33.2 & 81.57 \\
\hline
\end{tabular}

proved by the refractive index (1.381) and transmittance (99.6\%). The optimized microemulsion formulation was observed completely dark under cross polarized light, which implies that the developed microemulsion was optically isotropic and was a colloidal dispersion. The conductivity of the formulation was found to be 
TABLE 10: EXPERIMENTAL AND PREDICTED VALUES FOR THE OPTIMIZED MICROEMULSION FORMULATION

\begin{tabular}{cccc}
\hline Response variable & Predicted value & Experimental value & Prediction error $^{\mathrm{b}}$ (\%) \\
\hline$Y_{1}$ & 26.145 & $25.8 \pm 1.2$ & -1.34 \\
$Y_{2}$ & 0.431 & $0.436 \pm 0.014$ & 1.15 \\
$Y_{3}$ & 81.023 & $82.89 \pm 5.74$ & 2.25 \\
\hline
\end{tabular}

${ }^{a}$ mean $\pm S D(n=3)$, bPrediction error $(\%)$ was calculated using the formula [(experimental value-predicted value)/experimental value $\times 100$

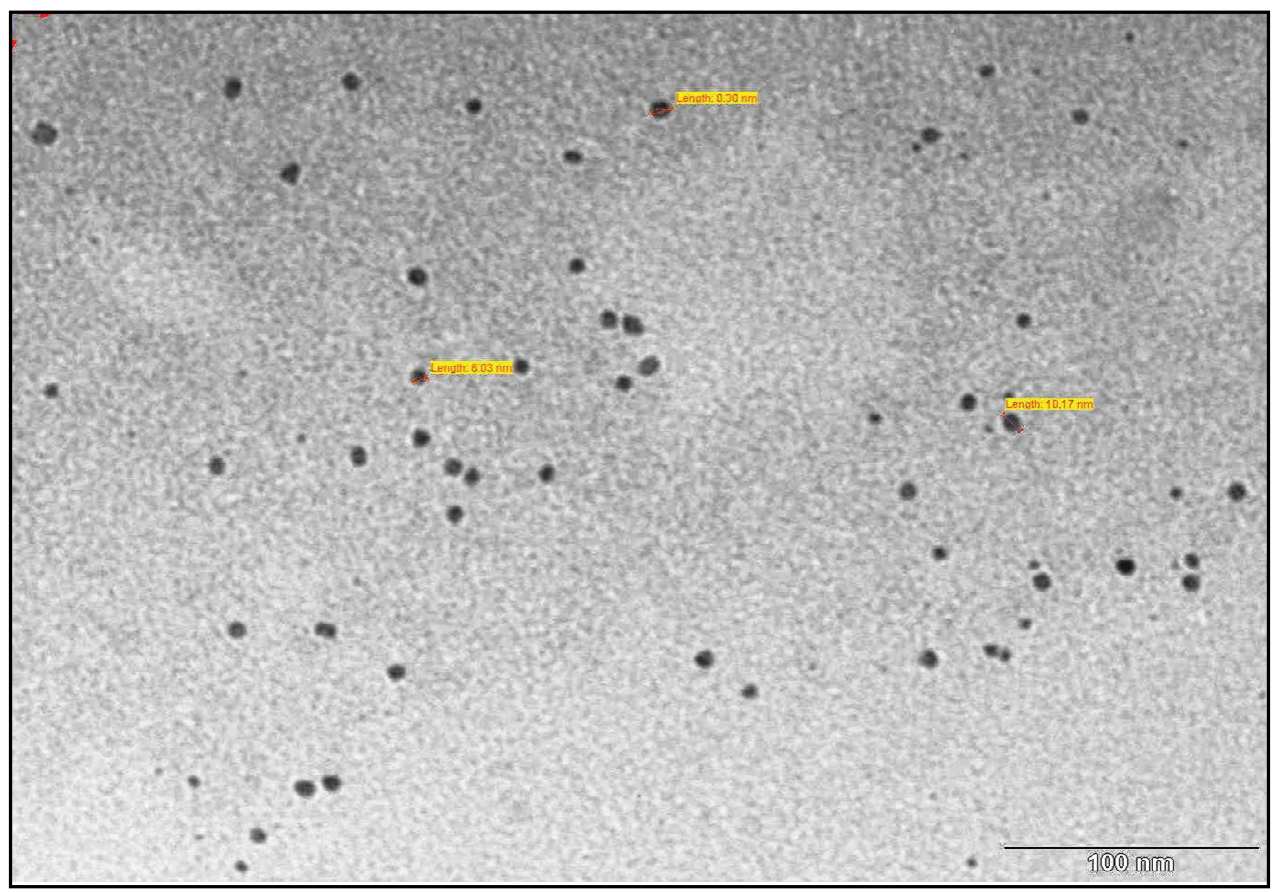

Fig. 5: Transmission electron micrograph of microemulsion of ciclopirox olamine.

$462 \pm 2.1 \mu \mathrm{Scm}^{-1}$ which confirmed the o/w nature of the developed microemulsion. The viscosity of the optimized microemulsion was found to be $10.53 \pm 0.86$ mPa.s.

The drug release study was performed to determine the possible effect of formulation excipients such as oil, surfactants, and gel forming agent on the release of drug from microemulsion gel formulation. The obtained drug release profiles of microemulsion and microemulsion based gel formulation were compared with each other and also with the release profile of plain drug solution. The comparative release profiles as presented in fig. 6 , clearly depict that the drug release was not affected by incorporation of microemulsion in Carbopol 940 gel base, as the release profiles of microemulsion and microemulsion based gel formulation are in close agreement with each other. It was also observed that the drug release from the plain drug solution was faster as compared to the microemulsion and microemulsion based gel formulation, perhaps, this difference is due to the partitioning of drug from oil droplet to the aqueous phase, prior to release. 


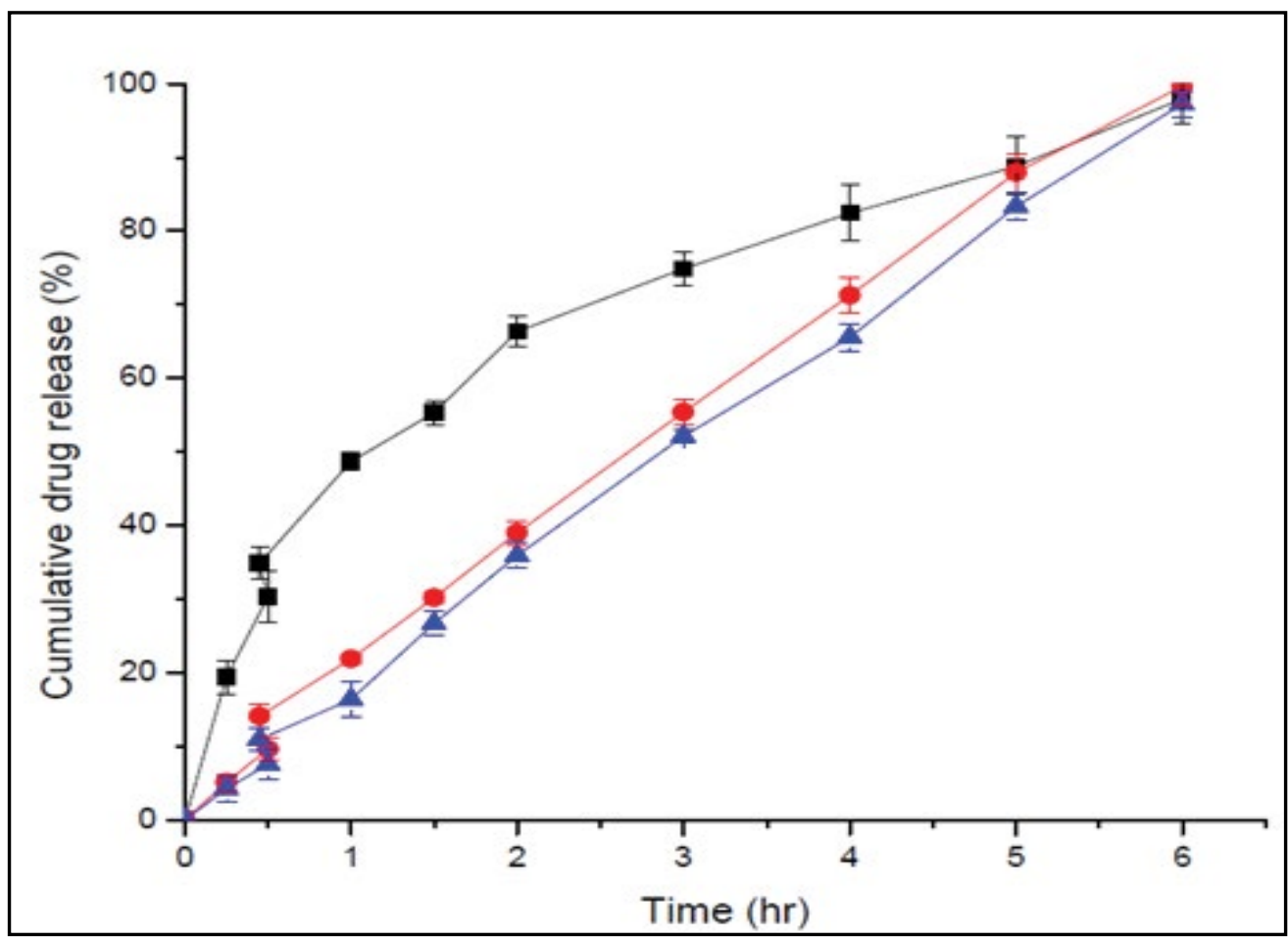

Fig. 6: In vitro drug release of ciclopirox olamine.

In vitro drug release from drug solution (-ø-), microemulsion (-๑-), and microemulsion based gel formulation (- $\Delta-)$ of ciclopirox olamine.

microemulsion produced consistent drug release from the gel formulation.

\section{Acknowledgements:}

Authors would like to acknowledge Sifavitor Srl(Milan, Italy) for generous supply of ciclopirox olamine, ABITEC (USA) for supply of gift samples of Capmul ${ }^{\circledR}$ PG-8 and Capmul ${ }^{\circledR}$ MCM, Gattefossé (France) for supply of gift samples of Transcutol ${ }^{\circledR}$ P, BASF India for supply of Cremophor ${ }^{\circledR}$ EL, and SICART, VV Nagar (Gujarat, India) for TEM analysis.

\section{Financial support and sponsorship:}

Nil.

\section{Conflicts of interest:}

There are no conflicts of interest.

\section{REFERENCES}

1. Elsayed MM. Development of topical therapeutics for management of onychomycosis and other nail disorders: a pharmaceutical perspective. J Control Release 2015;199:132-44.

2. Hui X, Shainhouse Z, Tanojo H, Anigbogu A, Markus GE, Maibach HI, et al. Enhanced human nail drug delivery: nail inner drug content assayed by new unique method. J Pharm Sci 2002;91:189-95.

3. Faergemann J, Baran R. Epidemiology, clinical presentation and diagnosis of onychomycosis. Br J Dermatol 2003;149:1-4.
4. Shivakumar HN, Juluri A, Desai BG, Murthy SN. Ungual and transungual drug delivery. Drug Dev Ind Pharm 2012;38:901-11.

5. Gupta AK, Uro M, Cooper EA. Onychomycosis therapy: past, present, future. J Drugs Dermatol 2010;9:1109-13.

6. Hafeez F, Hui X, Chiang A, Hornby S, Maibach H. Transungual delivery of ketoconazole using novel lacquer formulation. Int J Pharm 2013;456:357-61.

7. Chouhan P, Saini TR. Hydration of nail plate: A novel screening model for transungual drug permeation enhancers. Int J Pharm 2012;436:179-82.

8. Hao J, Smith KA, Li SK. Chemical method to enhance transungual transport and iontophoresis efficiency. Int $\mathrm{J}$ Pharm 2008;357:61-9.

9. Khengar R, Jones S, Turner R, Forbes B, Brown M. Nail swelling as a preformulation screen for the selection and optimisation of ungual penetration enhancers. Pharm Res 2007;24:2207-12.

10. Murdan S, Hinsu D, Guimier M. A few aspects of transonychial water loss (TOWL): inter-individual, and intraindividual inter-finger, inter-hand and interdayvariabilities, and the influence of nail plate hydration, filing and varnish. Eur J Pharm Biopharm 2008;70:684-9.

11. Nogueiras-Nieto L, Gómez-Amoza JL, Delgado-Charro MB, Otero-Espinar FJ. Hydration and N-acetyl-1-cysteine alter the microstructure of human nail and bovine hoof: implications for drug delivery. J Control Release 2011;156:337-44.

12. Kobayashi $\mathrm{Y}$, Miyamoto $\mathrm{M}$, Sugibayashi K, Morimoto $\mathrm{Y}$. Enhancing effect of N-acetyl-L-cysteine or 2-mercaptoethanol on the in vitro permeation of 5-fluorouracil or tolnaftate through the human nail plate. Chem Pharm Bull 1998;46:1797-802.

13. Malhotra GG, Zatz JL. Investigation of nail permeation 
enhancement by chemical modification using water as a probe. J Pharm Sci 2002;91:312-23.

14. Ciotti S. Lateral diffusion of a novel antifungal nanoemulsion in vitro human cadaver skin studies. Proceedings of American Association of Pharmaceutical Scientists Annual Meeting and Exposition. 2008. Atlanta, Georgia, USA.

15. Pal P, Thakur RS, Ray S, Mazumder B. Design and development of a safer noninvasive transungual drug delivery system for topical treatment of onychomycosis. Drug Dev Ind Pharm 2015;41:1095-9.

16. Barot BS, Parejiya PB, Patel HK, Gohel MC, Shelat PK. Microemulsion-based gel of terbinafine for the treatment of onychomycosis: Optimization of formulation using D-optimal design. AAPS PharmSciTech 2012;13:184-92.

17. Gunt HB, Kasting GB. Effect of hydration on the permeation of ketoconazole through human nail plate in vitro. Eur J Pharm Sci 2007;32:254-60.

18. Nahata T, Saini TR. D-optimal designing and optimization of long acting microsphere-based injectable formulation of aripiprazole. Drug Dev Ind Pharm 2008;34:668-75.

19. Kawakami K, Yoshikawa T, Hayashi T, Nishihara Y, Masuda K. Microemulsion formulation for enhanced absorption of poorly soluble drugs II. In vivo study. J Control Release 2002;81:75-82.

20. El-Malah Y, Nazzal S, Khanfar NM. D-optimal mixture design: Optimization of ternary matrix blends for controlled zero order drug release from oral dosage forms. Drug Dev Ind Pharm 2006;32:1207-18.

21. Chouhan P, Saini TR. Development and validation of a HPLC method for direct estimation of ciclopirox olamine in ex vivo transungual permeation studies. Indian Drugs 2016;53:32-9.

22. Murdan S. Drug delivery to the nail following topical application. Int J Pharm 2002;236:1-26.

23. Chouhan P, Saini TR. Hydroxypropyl-B-cyclodextrin: A novel transungual permeation enhancer for development of topical drug delivery system for onychomycosis. J Drug Deliv 2014;2014:7.

24. Ho RJY, Gibaldi M. Biotechnology and biopharmaceuticals: transforming proteins and genes into drugs. 2nd ed. NJ: Wiley-Blackwell; 2013. p. 446.

25. Purdon $\mathrm{CH}$, Smith EW, Surber C. Retardation strategies for sunscreen agents. In: Smith EW, Maibach HI, editors. Percutaneous penetration enhancers. Boca Raton: Taylor and Francis Group; 2006. p. 373-381. 